SEABRA JÚNIOR, S.; GADUN, J.; CARDOSO, A.I.I. Produção de pepino em função da idade das mudas produzidas em recipientes com diferentes volumes de substrato. Horticultura Brasileira, Brasília, v.22, n.3, p.610-613, ,jul-set 2004.

\title{
Produção de pepino em função da idade das mudas produzidas em reci- pientes com diferentes volumes de substrato
}

\author{
Santino Seabra Júnior ${ }^{1}$; Juliana Gadum¹; Antonio Ismael Inácio Cardoso ${ }^{2}$ \\ ${ }^{2}$ UNESP-FCA, DPV/Horticultura, C. Postal 237, 18603-970 Botucatu-SP; E-mail: santinoseabra@ fca.unesp.br; ${ }^{1}$ Doutorandos
}

\section{RESUMO}

Estudou-se o efeito do volume de substrato e da idade das mudas na produção de pepino japonês 'Hokuho' sob ambiente protegido na área experimental da UNESP, de março a julho/2000. Os tratamentos consistiram em dois volumes de substrato (34,6 e 121,2 $\mathrm{cm}^{3} \mathrm{em}$ bandeja de poliestireno expandido) e quatro idades das mudas (19;24; 29 e 34 dias após a semeadura). O delineamento experimental foi em blocos ao acaso, com cinco repetições e cinco plantas por parcela. Foram avaliados no dia do transplante o número de folhas, área foliar, comprimento, massa fresca e seca da parte aérea das mudas e, após o transplante, a produção precoce (porcentagem da produção nos primeiros 20 dias de colheita), produção de frutos (número e massa) e produção comercial (número e massa). Nas condições deste experimento, obteve-se maior precocidade com mudas de pepino produzidas em maior volume de substrato. Porém, a produção de frutos não apresentou diferença estatística quando utilizou-se mudas de pepino com menos de duas folhas produzidas em menor volume de substrato. A produção comercial foi superior com mudas produzidas em bandejas com maior volume de substrato. A idade não influenciou a produção comercial de frutos em mudas produzidas em volume de substrato maior, porém, quanto mais velhas as mudas produzidas em recipientes com menor volume de substrato, menor a produção destas plantas.

Palavras-chave: Cucumis sativus, produção de mudas, crescimento.

\author{
ABSTRACT \\ Effect of tray cell size and seedling age on cucumber \\ production
}

The effect of the cell size and seedling transplanting age on the production of cucumber 'Hokuho' under protected cultivation was studied, from March to July 2000 in Botucatu, São Paulo State, Brazil. The treatments resulted from the combination of two tray cell sizes $\left(34.6\right.$ and $\left.121.2 \mathrm{~cm}^{3}\right)$ and four seedling transplanting ages (19; 24; 29 and 34 days after sowing), evaluated in a randomized block design, with five replications and five plants per plot. During the transplanting period we evaluated the number of leaves, leaf area, seedling height, fresh and dry mass, and after transplanting, the early production (percentage of the production in the first 20 days of harvesting) and total yield of fruits (number and mass of fruits and commercial fruits). Higher early production was obtained with cucumber seedlings produced in large sized trays. No significant statistical differences were observed for total fruit yield when seedlings were produced in small sized trays and less than two leaves at transplanting age. The commercial production was improved when seedlings were produced in larger sized trays. Transplanting age had no influence over the commercial yield of fruits when seedlings were obtained in large sized trays. However, a reduction of commercial fruit production was observed in plants whose seedlings were transplanted later and produced in trays with smaller cells.

Keywords: Cucumis sativus, seeding production, growth.

\section{(Recebido para publicação em 25 de maio de 2003 e aceito em 2 de abril de 2004)}

\begin{abstract}
A produção de mudas em bandejas iniciou-se em 1985, com tomate, difundindo-se para outras culturas e hoje é utilizada também para produção de pepino (Cucumis sativus). Essa técnica é bastante vantajosa e propicia redução do ciclo da planta no campo ou em ambiente protegido, minimiza o custo com mão de obra, principalmente com tratos culturais iniciais (desbaste, capinas, irrigações e pulverizações) e melhora o aproveitamento das sementes, produzindo-se com cada unidade viável uma muda além de aumentar a uniformidade das mudas (Minami, 1995; Borne, 1999).

Pode-se encontrar, dependendo do modelo, diferentes tipos de bandejas, variando o volume de substrato disponível na célula. $\mathrm{O}$ volume de substrato disponível para o desenvolvimento radicular pode influenciar no desenvol-
\end{abstract}

vimento das mudas. A restrição radicular pode afetar o crescimento, a fotossíntese, o teor de clorofila nas folhas, a absorção de nutrientes e água, a respiração, o florescimento, bem como a produção (NeSmith e Duval, 1998). Maior massa de raízes em recipientes pequenos contribui para a redução do espaço poroso e maior competição por oxigênio. As mudas com sistema radicular restringido, quando transplantadas para o campo, são freqüentemente incapazes de compensar a evapotranspiração, mesmo se bem irrigadas após o transplante (Pereira e Martinez, 1999). Foram observadas diferenças no volume de substrato influenciando o desenvolvimento das mudas de beterraba (Echer et al., 2000), alface (Silva et al.; 2000a); brócolos (Silva et al., 2000b), berinjela (Barnabé et al., 1994a), pimentão (Barnabé et al., 1994b) e tomate (Barros, 1997). Em pepino, Barros (1997), ao estudar o comportamento de diferentes recipientes na produção de mudas, utilizando bandejas de 200 células com volume de 16 $\mathrm{cm}^{3}$ e 128 células com volume de 36 e $72 \mathrm{~cm}^{3}$, verificou que quanto maior o volume das células, maior o peso total, peso de matéria seca da parte aérea, das raízes e também maior área foliar das mudas. Entretanto, não foi avaliada a produção de frutos.

A idade da muda é outro fator que pode afetar a planta no campo, pois o desenvolvimento radicular da muda é dependente não só do volume de substrato disponível, mas também do tempo em que a raiz fica em contato com esse substrato. Se a muda for mantida por um período muito grande na bande- 
Produção de pepino em função da idade das mudas produzidas em recipientes com diferentes volumes de substrato

Tabela 1. Número de folhas (NF), altura média (AM), massa seca (MS) e massa fresca (MF) de mudas de pepino em função do volume de substrato e idade das mudas. Botucatu, UNESP, 2000.

\begin{tabular}{|c|c|c|c|c|c|c|c|c|}
\hline \multirow{3}{*}{ Idade da muda (dias) } & \multicolumn{8}{|c|}{ Volume de substrato $\left(\mathrm{cm}^{3}\right)$} \\
\hline & 34,6 & 121,2 & 34,6 & 121,2 & 34,6 & 121,2 & 34,6 & 121,2 \\
\hline & \multicolumn{2}{|c|}{ NF } & \multicolumn{2}{|c|}{$\mathrm{AM}(\mathrm{mm})$} & \multicolumn{2}{|c|}{ MS (g) } & \multicolumn{2}{|c|}{ MF (g) } \\
\hline 19 & $1,0 \mathrm{Bc}$ & $1,8 \mathrm{AC}$ & $41,5 \mathrm{Ab}$ & $66,4 \mathrm{Ac}$ & $0,2 \mathrm{AC}$ & $0,3 \mathrm{Ac}$ & $1,3 \mathrm{AC}$ & $2,3 A C$ \\
\hline 24 & $1,8 \mathrm{Ab}$ & $2,0 \mathrm{Ac}$ & $68,4 \mathrm{Bb}$ & $106,0 \mathrm{Ab}$ & $0,3 \mathrm{Abc}$ & $0,5 \mathrm{Abc}$ & $2,1 \mathrm{Bbc}$ & $4,2 \mathrm{Ab}$ \\
\hline 29 & $2,5 \mathrm{Aa}$ & $2,5 \mathrm{Ab}$ & $113,9 \mathrm{Aa}$ & $140,5 \mathrm{Ab}$ & $0,6 \mathrm{Aab}$ & $0,8 \mathrm{Ab}$ & 3,1 Bab & $4,8 \mathrm{Ab}$ \\
\hline 34 & $2,7 \mathrm{Ba}$ & 3,4 $\mathrm{Aa}$ & $135,0 \mathrm{Ba}$ & $214,5 \mathrm{Aa}$ & $0,6 \mathrm{Ba}$ & $1,2 \mathrm{Aa}$ & $3,9 \mathrm{Ba}$ & $7,7 \mathrm{Aa}$ \\
\hline CV\% & \multicolumn{2}{|c|}{10,49} & \multicolumn{2}{|c|}{14,15} & \multicolumn{2}{|c|}{23,04} & \multicolumn{2}{|c|}{16,01} \\
\hline
\end{tabular}

Médias seguidas de mesma letra, em cada característica, maiúscula na linha e minúscula na coluna, não diferem estatisticamente pelo teste de Tukey a $5 \%$ de probabilidade.

ja, ela poderá apresentar deficiência de nutrientes e oxigênio, podendo ocorrer até mesmo enovelamento das raízes. Isto geralmente acontece pelo atraso no transplante. O tempo em que as mudas permanecem com seu sistema radicular restringido deve ser o mínimo possível (Pereira e Martinez, 1999). Para as cucurbitáceas é recomendado que se transplante as mudas com três semanas (Borne, 1999), pois estas espécies têm rápido desenvolvimento.

Para produtores de mudas, ocorre a tendência de se comercializar mudas mais novas, para reduzir o tempo destas nos viveiros de produção. Os produtores preferem mudas mais desenvolvidas. Provavelmente esta preferência está relacionada com a facilidade de transplante, pois estas apresentam um sistema radicular compacto que não se quebra no momento da retirada das bandejas.

Objetivou-se neste trabalho estudar o efeito do volume de substrato e da idade das mudas na produção de pepino japonês sob ambiente protegido.

\section{MATERIAL E MÉTODOS}

O experimento foi conduzido na UNESP em Botucatu, entre março e ju1ho/2000. As temperaturas mínimas e máximas na estufa na fase de muda oscilaram entre $8-18^{\circ} \mathrm{C}$ e $20-28^{\circ} \mathrm{C}$ e após o transplante oscilaram entre $4-19^{\circ} \mathrm{C}$ e $25-34^{\circ} \mathrm{C}$, respectivamente.

Realizou-se análise química do solo e este foi adubado seguindo as recomendações de Trani et al. (1996). A irrigação utilizada no campo foi por gotejamento. Os tratos culturais, controle de pragas e doenças foram realizados de acordo com a necessidade da cultura.
O delineamento experimental foi em blocos casualizados, onde foram implantados oito tratamentos em esquema fatorial $2 \times 4$, utilizando dois volumes de substrato $\left(34,6 \mathrm{~cm}^{3}\right.$ e $\left.121,2 \mathrm{~cm}^{3}\right)$ e quatro idades de mudas $(19,24,29$ e 34 dias após a semeadura). Para obter o volume de $34,6 \mathrm{~cm}^{3}$ utilizou-se bandejas de poliestireno expandido tipo $128 / 6$, com 128 células, altura da bandeja de $6,2 \mathrm{~cm}$ e largura da célula de $3,5 \mathrm{~cm}$, e para o volume de $121,2 \mathrm{~cm}^{3}$ utilizou-se bandejas 72/12 com 128 células, altura da bandeja de $12 \mathrm{~cm}$ e largura da célula de $5 \mathrm{~cm}$. O experimento foi instalado com cinco repetições, utilizando-se cinco plantas por parcela.

As semeaduras foram realizadas no mês de março a cada cinco dias, utilizando-se o híbrido Hokuho, possibilitando o transplante em um único dia (18/ 04/2000), em espaçamento de 1,00 x $0,45 \mathrm{~m}$. Caracterizou-se as mudas no dia do transplante, coletando três amostras de cada tratamento. Avaliou-se o número de folhas, área foliar, comprimento da parte aérea, massa fresca e seca da parte aérea.

A colheita de frutos com aproximadamente $20 \mathrm{~cm}$ de comprimento foi realizada a cada dois dias, iniciada aos 34 dias após o transplante e encerrada aos 60 dias após a primeira colheita. Avaliou-se a produção total e comercial (frutos pouco tortos ou retos) em número e massa. Para avaliação da precocidade, considerou-se a porcentagem de frutos colhidos nos primeiros 20 dias de colheita, em relação à produção.

Todas as características foram analisadas considerando-se a média por planta. $\mathrm{Na}$ análise utilizou-se o programa estatístico Estat, realizando-se o teste
F, análise de regressão e comparação de médias pelo teste de Tukey, a 5\% de probabilidade. Realizaram-se correlações entre as médias obtidas na caracterização de mudas e na produção.

\section{RESULTADOS E DISCUSSÃO}

\section{Avaliação das mudas}

Observou-se que mudas produzidas no volume de substrato maior (121,2 $\left.\mathrm{cm}^{3}\right)$ apresentaram o dobro de área foliar $\left(40,63 \mathrm{~cm}^{2}\right)$ quando comparadas àquelas produzidas em volume de substrato menor $\left(34,6 \mathrm{~cm}^{3}\right)$, independente da idade das mudas. Esta tendência de aumento da área foliar também foi relatada em melancia (Liu e Latimer, 1995), melão (Maynard, 1996), pepino (Barros, 1997), quiabo (Modolo, 1998) e alface (Silva et al., 2000a).

Para número de folhas, altura, massa fresca e seca da parte aérea das mudas, observou-se tendência de paralisação do crescimento em mudas produzidas em volume menor $\left(34,6 \mathrm{~cm}^{3}\right)$, onde as mais velhas ( 29 e 34 dias) não diferiram entre si (Tabela 1). Entretanto observou-se que as mudas produzidas em maior volume $\left(121,2 \mathrm{~cm}^{3}\right)$ não sofreram restrição no seu crescimento concordando com o relatado por Zárate (1980) em tomate. Os resultados observados podem ser explicados pela influência da restrição do sistema radicular no desenvolvimento da parte aérea (Pereira e Martinez, 1999), onde volumes menores de substrato restringem as raízes, reduzindo a oxigenação, a disponibilidade de nutrientes, água e outros elementos essenciais para o desenvolvimento das plântulas. 
Tabela 2. Correlação entre as características avaliadas na fase de mudas, no dia do transplante e a produção de frutos em massa $(\mathrm{PF})$, número de frutos $(\mathrm{NF})$, produção de frutos comerciais em massa (PFC) e número de frutos comerciais (NF) por planta, com mudas produzidas em volume de 34.6 e $121,2 \mathrm{~cm}^{3}$. Botucatu, UNESP, 2000.

\begin{tabular}{|c|c|c|c|c|c|}
\hline $\begin{array}{c}\text { Caracteristicas na fase de } \\
\text { mudas }\end{array}$ & $\begin{array}{c}\text { Volume de } \\
\text { substrato } \\
\left(\mathrm{cm}^{3}\right)\end{array}$ & $P F(g)$ & NF & $\operatorname{PFC}(g)$ & NFC \\
\hline Diâmetro (mm) & 34.6 & $-0,97^{5}$ & $-0,98^{5}$ & $-0,90 \mathrm{~ns}$ & $-0,94 n s$ \\
\hline Altura $(\mathrm{mm})$ & 34.6 & $-0,94^{5}$ & $-0,92 \mathrm{~ns}$ & $-0,73$ ns & $-0,95^{5}$ \\
\hline Número de folhas & 34.6 & $-0,99^{1}$ & $-0,98^{5}$ & $-0,81 \mathrm{~ns}$ & $-0,97^{5}$ \\
\hline Área foliar $\left(\mathrm{cm}^{2}\right)$ & 34.6 & $-0,92 \mathrm{~ns}$ & $-0,95^{5}$ & $-0,96^{5}$ & $-0,86 \mathrm{~ns}$ \\
\hline Massa fresca da parte aérea $(\mathrm{g})$ & 34.6 & $-0,92 \mathrm{~ns}$ & $-0,90 \mathrm{~ns}$ & $-0,77 \mathrm{~ns}$ & $-0,91 \mathrm{~ns}$ \\
\hline Massa seca da parte aérea(g) & 34.6 & $-0,95^{5}$ & $-0,92 \mathrm{~ns}$ & $-0,71 \mathrm{~ns}$ & $-0,97^{5}$ \\
\hline Diâmetro (mm) & 121.2 & $0,88 \mathrm{~ns}$ & $0,75 \mathrm{~ns}$ & $0,08 \mathrm{~ns}$ & $0,54 \mathrm{~ns}$ \\
\hline Altura (mm) & 121.2 & $0,92 \mathrm{~ns}$ & $0,95^{5}$ & $-0,00 \mathrm{~ns}$ & $0,79 \mathrm{~ns}$ \\
\hline Número de folhas & 121.2 & $0,91 \mathrm{~ns}$ & $0.97^{5}$ & $-0,04 \mathrm{~ns}$ & $0,86 \mathrm{~ns}$ \\
\hline Area foliar $\left(\mathrm{cm}^{2}\right)$ & 121.2 & $0,99^{1}$ & $0,87 \mathrm{~ns}$ & $-0,25 \mathrm{~ns}$ & $0,87 \mathrm{~ns}$ \\
\hline Massa fresca da parte aérea $(g)$ & 121.2 & $0,90 \mathrm{~ns}$ & $0,92 \mathrm{~ns}$ & 0,09 ns & $0,71 \mathrm{~ns}$ \\
\hline Massa seca da parte aérea $(g)$ & 121.2 & $0,93 \mathrm{~ns}$ & $0.95^{5}$ & $0,03 n s$ & $0,82 \mathrm{~ns}$ \\
\hline
\end{tabular}

${ }^{1}$ e ${ }^{5}$ Significativo pelo teste $\mathrm{F}$ a 1 e $5 \%$, respectivamente. ${ }^{\text {NS }}$ Não significativo pelo teste $\mathrm{F}$
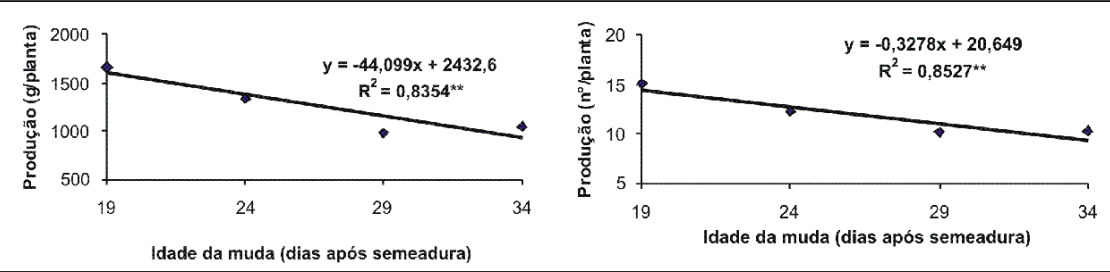

Figura 1. Produção em número e massa de frutos (g) por planta em função da idade das mudas em volume de substrato de 34,6 $\mathrm{cm}^{3}$. Botucatu, UNESP, 2000.

Após o transplante, mudas mais velhas, de maior tamanho no transplante (Tabela 1), apresentaram menor desenvolvimento (altura e número de folhas) no campo e, mudas produzidas em volume de substrato maior originaram plantas maiores e com mais folhas que as produzidas em volume menor. $\mathrm{Mu}$ das produzidas em volumes de células maiores são mais vigorosas, apresentando uma relação parte aérea/raiz mais equilibrada, proporcionando um melhor desenvolvimento das plantas após o transplante (Pereira e Martinez, 1999).

\section{Produção}

Mudas produzidas em maior volume de substrato $\left(121,2 \mathrm{~cm}^{3}\right)$ foram mais precoces sendo que $35 \%$ do total dos frutos, foram colhidos nos primeiros 20 dias de colheita. Por outro lado, em mudas produzidas em volume menor $\left(34,6 \mathrm{~cm}^{3}\right)$, apenas $23 \%$ dos frutos foram colhidos neste período em relação a produção total (número de frutos). Quando se considerou apenas frutos comerciais, mudas produzidas em maior volume de substrato tiveram $41 \%$ dos frutos colhidos nos primeiros 20 dias, enquanto mudas produzidas em volume menor apresentaram apenas $28 \%$. Este resultado é de grande relevância, pois assegura ao produtor uma maior remuneração no inicio do ciclo. A precocidade é reflexo da qualidade das mudas, já que estas apresentaram maior equilíbrio da parte aérea com o sistema radicular e ausência de estresse após o transplante. A obtenção de maior precocidade em mudas produzidas em volume de substrato maior também foi relatada em pimentão (Weston, 1988), berinjela (Harmon et al., 1991), couve-flor e brócolos (Jones et al., 1991) e tomate (Weston e Zandstra, 1986).

A idade das mudas não afetou a precocidade (cerca de $30 \%$ dos frutos foram colhidos nos primeiros 20 dias, independente da idade das mudas), concordando com os resultados obtidos em tomate (Leskovar et al., 1991), abobri- nha (NeSmith, 1993) e melancia (Vavrina et al., 1993).

Não houve influência da idade das mudas produzidas em volume maior $\left(121,2 \mathrm{~cm}^{3}\right)$, com a produção de frutos por planta (massa e número), variando de 1514 a 1702 gramas por planta. Entretanto, quanto mais nova a muda produzida em volume de $34,6 \mathrm{~cm}^{3}$, maior a produção (Figura 1), sendo que a mudas com 19 dias apresentaram uma produção (gramas e número) 63\% maior que as com 29 e 34 dias. Provavelmente estas mudas mais velhas tiveram seu sistema radicular restringido, passando do ponto ideal de transplante, afetando assim a produção final, o que não acontece com mudas produzidas em volume maior. Ressalta-se que as mudas mais novas (19 e 24 dias) no menor volume de substrato apresentaram menos que 2 folhas definitivas, enquanto que as mais velhas (29 e 34 dias), apresentaram mais de 2 folhas (Tabela 1). Portanto, talvez 2 folhas definitivas seja o limite para o transplante de mudas de pepino quando se utiliza bandeja com células de 34,6 $\mathrm{cm}^{3}$ (128 células). Quanto ao número de dias, o resultado concorda com Barros (1997), o qual recomenda a utilização de mudas com até 24 dias após a semeadura para o volume de substrato de 34,6 $\mathrm{cm}^{3}$. Todavia, de acordo com as condições ambientais, principalmente temperatura, a velocidade de desenvolvimento das mudas pode variar, portanto, o número de dias pode não ser um bom parâmetro. O número de folhas é mas confiável, pois pode ser "reproduzido" e avaliado em quaisquer condições ambientais.

$\mathrm{Na}$ comparação dos volumes de substrato, obteve-se maior produção com mudas produzidas em maior volume, somente nas mudas mais velhas (29 e 34 dias), obtendo-se produções (g e $\mathrm{n} \%$ planta) de 1677,02 e 14,86 aos 29 dias e 1701,76 e 16,80 aos 34 dias. Por outro lado, em mudas produzidas em volume menor $\left(34,6 \mathrm{~cm}^{3}\right)$, a produção $\left(\mathrm{g}\right.$ e $\mathrm{n}^{\circ}$ planta) foi de 987,58 e 10,13 aos 29 dias e 1052,74 e 10,33 aos 34 dias. Hall (1989) e Liu e Latimer (1995) em melancia e Modolo (1998) em quiabo observaram aumento de produção em plantas oriundas de mudas produzidas em volume maior de substrato, entretanto 
não levaram em consideração o efeito da idade das mudas.

A produção comercial não foi afetada pela idade das mudas, variando de 912,01 a 1016,51 gramas e de 8,30 a 8,73 frutos por plantas. Estes resultados estão de acordo com o observado em plantas de tomate (Leskovar et al., 1991), abobrinha (NeSmith, 1993) e melancia (Vavrina et al., 1993).

O volume de substrato foi fator determinante na produção comercial. Quando as mudas foram produzidas em volume de substrato maior $\left(121,2 \mathrm{~cm}^{3}\right)$ obteve-se uma produção (g e $\mathrm{n}^{\circ}$ /planta) de 1099,05 e 9,53 , enquanto que o volume menor produziu 824,02 gramas e 7,08 frutos/planta. O acréscimo na produção comercial foi de $25 \%$ quando se utilizou mudas produzidas em volume maior de substrato.

Quando se utilizou mudas que não sofreram estresse no transplante e no desenvolvimento pós transplante, obteve-se maior rendimento de frutos com características adequadas à comercialização, concordando com o resultado obtido por Liu e Latimer (1995) em melancia.

Foram obtidas correlações positivas e elevadas entre a fase de muda e produção total por planta, mas não para a produção comercial por planta, quando as mudas foram produzidas em volume de substrato maior $\left(121,2 \mathrm{~cm}^{3}\right)$ (Tabela 2). Destacaram-se as correlações área foliar por produção de frutos em massa por planta (1\%), comprimento, número de folhas e massa seca da parte aérea por número de frutos por planta $(5 \%)$. Quanto maior o comprimento, número de folhas e área foliar, maior a produção de frutos por planta em massa e em número.

Em mudas produzidas em menor volume de substrato $\left(34,6 \mathrm{~cm}^{3}\right)$, todas as correlações foram negativas, sendo a maioria significativa. Portanto, quanto maior a muda (diâmetro, altura, número de folhas, área foliar, massa fresca e seca da parte aérea), dentro dos estádios estudados, menor a produção total de frutos por planta bem como a comercial (Tabela 2). Assim, mudas maiores, dentro do intervalo avaliado, foram as de pior qualidade. Deste modo, produtores de pepino que produzem mudas em bandeja de
128 células $\left(34,6 \mathrm{~cm}^{3}\right)$ e tem preferência por mudas grandes e "vigorosas" podem estar perdendo produção e quanto mais passada a muda, maior a perda.

Considerando as condições em que foi desenvolvido o experimento, pode-se concluir que quando se prefere utilizar bandejas de 128 células (tipo 128/6) com 34,6 $\mathrm{cm}^{3}$ de volume, deve-se atentar à idade de transplante da muda, dando preferência para mudas com no máximo 2 folhas definitivas. Mas, se utilizar bandeja de 72 células, a muda pode ser transplantada mais velha, não havendo perda de produção até a idade avaliada no experimento, 34 dias após semeadura com cerca de 3 a 4 folhas definitivas.

\section{AGRADECIMENTOS}

Os autores agradecem ao suporte técnico da Fapesp e à Capes pela concessão de bolsa de mestrado ao primeiro autor, que possibilitaram a realização do projeto.

\section{LITERATURA CITADA}

BARNABÉ, F.A., GIORGETTI, J.R., GOTO, R Influência de três tipos de bandejas, para a produção de mudas de berinjela. Horticultura Brasileira, Brasília, v.18, Suplemento, p.71, 1994a.

BARNABÉ, F.A., GIORGETTI, J.R., GOTO, R Influência de três tipos de bandejas, para a produção de mudas de pimentão. Horticultura Brasileira, Brasília, v.18, Suplemento, p.71, 1994b.

BARROS, S.B.M. Avaliação de recipientes na produção de mudas de tomate (Lycopersicon esculentum Mill.) e pepino (Cucumis sativus L.). 1997. 70p. (Tese mestrado), ESALQ, USP, Piracicaba.

BORNE, H.R. Produção de mudas de hortaliças. Guaíba: Agropecuária, 1999. 187p.

ECHER, M.M., ARANDA, A.N., BORTOLAZZO, E.D., BRAGA, J.S. TESSARIOLI NETO, J. Efeito de três substratos e dois recipientes na produção de mudas de beterraba. Horticultura Brasileira, Brasília, v.18, Suplemento, p.509-510, 2000.

FILGUEIRA, F.A.R. Cucurbitáceas: a família da abóbora. In: FILGUEIRA, F.A.R. Manual de olericultura: cultura e comercialização de hortaliças. 1 ed. Viçosa: UFV, 2000. p.346-350.

HALL, M.R. Cell size of seedling containers influences early vine growth and yield of transplanted watermelon. Hortscience, v.24, p.771-3, 1989.

HARMON, R., WESTON, L.A., JONES, T Effect of root cell size and transplant age on yield of transplanted eggplant. HortScience, v.26, p.688, 1991.
JONES, R.T., WESTON, L.A., HARMON, R. Effect of root cell size and transplant age on cole crop yields. Hortscience, v.26, p.688, 1991.

LESKOVAR, D.I., CANTLIFFE, D.J., STOFFELLA, P.J. Growth and yield of tomato plants in response to age of transplants. Journal of the American Society for Horticultural Science, v.116, n.3, p.416-420, 1991.

LIU, A., LATIMER, J.G. Root cell volume in the planter flat affects watermelon seedling development and fruit yield. Hortscience, v.30, p.242-246, 1995.

MAYNARD, E.T., VAVRINA, C.S., SCOTT, W.D. Containerized muskmelon transplants: cell volume effects on pretransplant development and subsequent yield. Hortscience, v.31, p.58-61, 1996.

MINAMI, K. Produção de mudas de alta qualidade em horticultura. São Paulo: T.A. Queiroz, 1995. 128p.

MODOLO, V.A. Avaliação de recipientes e substratos para a produção de mudas de quiabeiro (Abelmoschus esculentus [L.] Moench.). 1998. 53p. (Tese mestrado), ESALQ, USP, Piracicaba. NESMITH, D.S. Transplant age influences summer squash growth and yield. Hortscience, v.28, p.618-20, 1993.

NESMITH, D.S., DUVAL, J.R. The effect of container size. HortTechnology, v.8, n.4, 495-498, 1998.

PEREIRA, P.R.G., MARTINEZ, H.E.P. Produção de mudas para o cultivo de hortaliças em solo e hidroponia. Informe agropecuário, Belo Horizonte, v.20, n.200/201, p.24-31, 1999.

SILVA, A.C.R., FERNANDES, H.S., MARTINS, S.R., SILVA, J.B., SCHIEDECK, G., ARMAS, E. Produção de mudas de alface com vermicompostos em diferentes tipos de bandeja. Horticultura Brasileira, Brasília, v.18, Suplemento, p.512-3, jul. 2000a.

SILVA, A.C.R., FERNANDES, H.S., HOPPE, M., MORAES, R.M.D., PEREIRA, R.P., JACOB JÚNIOR, E.A. Produção de mudas de brócolis com vermicompostos em diferentes tipos de bandeja. Horticultura Brasileira, Brasília, v.18, Suplemento, p.514-5, jul. 2000b.

TRANI, P.E., PASSOS, F.A., MELO, A.M.T., SCIVITTARO, V.B., NAGAI, H. Recomendações de adubação e calagem de pepino. 2 ed. Boletim Técnico do Instituto Agronômico. Campinas, n.100, p.165, 1996.

VAVRINA, C.S., OLSON, S., CORNELL, J.A. Watermelon transplant age: influence on fruit yield. Hortscience, v.28, p.789-790, 1993.

WESTON, L.A. Effect of flat cell size, transplant age, and production site on growth and yield of pepper transplants. Hortscience, v.23, p.709-11, 1988.

WESTON, L.A., ZANDSTRA, B.H. Effect of root container size and location of production on growth and yield of tomato transplants. Journal of the American Society for Horticultural Science, v.111, n.4, p.498-501, 1986.

ZÁRATE, N.H. Efeito da idade e da profundidade de transplante de mudas sobre a produção de tomate (Lycopersicum esculentum Mill). 1980. 32p. (Tese mestrado), UFV, Viçosa. 